or nitrogen, but neither method was used in these cases. Both patients probably acquired the infection from their mothers and the meningitis was treated in the conventional way once the diagnosis was confirmed but neither responded despite several changes of antibiotics. It was only after identification of $M$. hominis and the institution of appropriate treatment based on the sensitivities of the organism that there was clinical improvement.

We thank Professor Hurley and Dr de Luvois of Queen Charlotte's Hospital, London for bacteriological identification in Case 1, the staff of the Mycoplasma Reference Laboratory for classification of the organisms, Miss J. Robinson and Miss P. Redmond for clerical help.

\section{References}

Klein, J. O., Buckland, D., and Finland, M. (1969). Colonisation of newborn infants by mycoplasmas. New England Journal of Medicine, 280, 1025-1030.

Remington, J. S., and Klein, J. O. (1976). Infectious Disease of the Fetus and Newborn Infant, p. 148. Saunders: Philadelphia.

Siber, G. R., Alpert, S., Smith, A. L., Juey-Shien, L. L., and McCormack, W. M. (1977). Neonatal central nervous system infection due to Mycoplasma hominis. Journal of Pediatrics, 90, 625-627.

Stokes, E. J. (1955). Human infection with pleuropneumonialike organisms. Lancet, 1, 276-279.

Correspondence to Dr W. C. Marshall, The Hospital for Sick Children, Great Ormond Street, London WC1N 3JH.

\title{
A clinical comparison of beclomethasone dipropionate delivered by pressurised aerosol and as a powder from a rotahaler
}

\section{A. T. EDMUNDS, SHEILA McKENZIE, MARIAN TOOLEY, AND S. GODFREY}

Department of Paediatrics and Neonatal Medicine, Hammersmith Hospital, Du Cane Road, London W12 OHS

SUMMARY 14 children with severe asthma were studied for 2 months in a double-blind cross-over trial to compare the efficacy of beclomethasone dipropionate delivered as an aerosol and as a powder from a rotahaler.* Inhalation via the aerosol was satisfactory in 13 patients, each of whom used the rotahaler correctly. Younger children preferred to use the rotahaler. Comparison of daily symptoms, twice daily peak expiratory flow rate (PEFR), and use of salbutamol during the 2 months of the trial showed that control of asthma was equally good, irrespective of the device used to deliver active beclomethasone.

There have been many studies demonstrating that beclomethasone dipropionate aerosol is safe and effective in the long-term management of severe childhood asthma (Morrow Brown and Storey, 1973; Godfrey and König, 1974; Lovera et al., 1976). However, some children have difficulty using pressurised aerosols correctly, and consequently they have been denied the benefit of this form of treatment. Recently beclomethasone dipropionate has

*Allen and Hanbury's.Research Division. become available in powder form mixed with a lactose base. It is dispensed in capsules which are used in a rotahaler* (Hallworth, 1977). This device requires less co-ordination for effective use as the patient has only to breathe through it to inhale the powder. We have conducted a 2-month doubleblind randomised cross-over trial to determine whether beclomethasone dipropionate dispensed in this way is as effective in controlling symptoms of asthma as the usual preparation delivered as a metred dose from a pressurised aerosol. We also tried to find out if there were any problems associated with the use of the rotahaler in paediatric outpatient practice.

\section{Patients and methods}

Seven boys and 7 girls (mean age $9 \cdot 7$ years, range $4 \cdot 8-15 \cdot 1$ years) were studied. They were all asthmatic and had previously been judged on clinical grounds to require treatment with beclomethasone. Before the trial they had been using beclomethasone regularly for a mean period of 1 year 10 months (range 0-5 years 5 months). 11 of them had failed to respond satisfactorily to treatment with sodium cromoglycate and one had failed to respond to treatment with regular theophylline. Two had 
previously been treated with alternate day oral prednisolone and had subsequently been weaned off this on to aerosol beclomethasone dipropionate. Three patients had required short courses of oral prednisolone during the previous year.

At the start of the trial all the patients were taught how to use both the aerosol and the rotahaler. At the end of the month each child was asked to demonstrate the use of both devices. He/she was given a score out of 10 for use of the aerosol. Droplet escape from nose or mouth, timing of aerosol release during inspiration, and size of breath taken (tidal or full vital capacity) were scored. It was noted whether the child was able to assemble the rotahaler correctly with the capsule in place, whether the powder fell on the floor, and whether he/she made an inspiratory effort great enough to inhale all the powder.

Throughout the trial the patients took two puffs of aerosol 4 times a day and powder from one capsule in the rotahaler 4 times a day. Each month one device contained active drug and the other an appropriate placebo. The order in which the patients received the drugs was randomly assigned by the hospital pharmacist and was not disclosed to the patients or the physicians until the trial was completed. All patients were given a salbutamol aerosol in addition to the beclomethasone to use as necessary for cough or wheeze. During the trial the patients recorded their symptoms each day in a diary card (Connolly and Godfrey, 1970). They also recorded peak expiratory flow rate (PEFR) every morning and evening. This was measured as the best of 3 attempts using a calibrated peak flow gauge (Airmed Ltd). The amount of salbutamol used to treat intermittent symptoms was also noted. Comparison of the results in the two treatment periods was made using paired $t$ tests.

\section{Results}

Use of inhalation devices. All children were able to use the rotahaler correctly and 13 achieved mean scores of $\mathbf{8}$ or more for aerosol inhalation technique. Two had not used an aerosol before the trial. One of these had a mean score of 5 for inhalation technique. The Table shows that younger children preferred to use the rotahaler while older ones preferred the aerosol. Although the figures are too few for statistical analysis there did not appear to be any relationship between the length of time of previous beclomethasone treatment and preference for device.

Response to treatment. Symptom scores, number of symptom-free days, morning and evening PEFR
Table Age of patients, time of previous experience with aerosol, and preferred device (aerosol or rotahaler)

\begin{tabular}{lll}
\hline $\begin{array}{l}\text { Age of patient } \\
\text { (years) }\end{array}$ & $\begin{array}{l}\text { Previous duration of } \\
\text { aerosol treatment } \\
\text { (years) }\end{array}$ & Preferred device \\
\hline 15.1 & $1 \cdot 3$ & Aerosol \\
13.8 & $2 \cdot 3$ & No preference \\
13.7 & 0.0 & No preference \\
12.8 & $1 \cdot 2$ & No preference \\
11.9 & $1 \cdot 3$ & No preference \\
10.7 & 5.4 & Aerosol \\
10.1 & $1 \cdot 3$ & Aerosol \\
9.8 & 2.9 & Aerosol \\
7.3 & 2.9 & No preference \\
7.1 & $1 \cdot 1$ & Rotahaler \\
6.9 & 0.0 & No preference \\
6.0 & 2.0 & Rotahaler \\
5.8 & 2.8 & Aerosol \\
4.9 & $1 \cdot 1$ & Rotahaler \\
\hline
\end{tabular}

results, and the amount of salbutamol used were recorded for each month of the trial. The mean symptom score was significantly lower during the month of treatment with active aerosol and placebo powder $(P=0.04)$, but there were no significant differences between the two periods for any of the other recorded parameters. The child who scored only 5 out of 10 for aerosol inhalation technique was as well in the month that he was taking aerosol as in the month that he was using the rotahaler. Of 8 patients who stated a preference for one type of device only 2 were controlled better during the month they were using that device.

\section{Discussion}

This trial has shown that beclomethasone dipropionate delivered from a rotahaler was as effective as that delivered by pressurised aerosol in controlling the symptoms of this selected group of asthmatic children. Most of the patients had been using the aerosol for some time and all but one were given a mean score of at least $\mathbf{8}$ for their aerosol inhalation technique. Preference for a particular type of device was not related to symptom score or PEFR recorded during the month of its use for active drug. However, the 3 patients who preferred to use the rotahaler were among the younger children in the trial. It is probable that the rotahaler would prove more effective than an aerosol for young children who have difficulty using pressurised aerosols. Provided inhalation is continued until all the powder from each capsule is used, there is far less chance that it will be delivered incorrectly. All our patients were able to use the device without difficulty.

It is concluded that beclomethasone powder delivered from a rotahaler is a useful addition to the therapeutic armoury for the management of severe asthma in childhood. 


\section{References}

Connolly, N., and Godfrey, S. (1970). Assessment of the child with asthma. Journal of Asthma Research, 8, 31-36.

Godfrey, S., and König, P. (1974). Treatment of childhood asthma for thirteen months and longer with beclomethasone dipropionate aerosol. Archives of Disease in Childhood, 49, 591-596.

Hallworth, G. W. (1977). An improved design of powder inhaler. British Journal of Clinical Pharmacology, 4, 689690.

Lovera, J., Cooper, D. M., Collins-Williams, C., Levison, H.,
Bailey, J. D., and Orange, R. P. (1976). Clinical and physiological assessment of asthmatic children treated with beclomethasone dipropionate. Journal of Allergy and Clinical Immunology, 57, 112-113.

Morrow Brown, H., and Storey, G. (1973). Beclomethasone dipropionate steroid aerosol in the treatment of perennial allergic asthma in children. British Medical Journal, 3, 161-164.

Correspondence to Dr A. T. Edmunds, Department of Child Health, Royal Hospital for Sick Children, St Michael's Hill, Bristol BS2 8BJ.

\title{
Cefuroxime plasma and CSF levels in children with meningitis
}

\author{
J. A. KUZEMKO AND S. R. WALKER
}

Paediatric Department, Peterborough District Hospital, and Glaxo Research Limited, Clinical Division, Greenford, Middlesex

SUMMARY Cefuroxime $(25 \mathrm{mg} / \mathrm{kg})$ given intravenously every four hours to 7 children with bacterial meningitis resulted in satisfactory therapeutic blood and CSF levels. All children made a full recovery and side effects were absent.

Bacterial meningitis in children carries a $10-15 \%$ mortality rate and there can be significant neurological damage in children who recover (Goldacre, 1977). The success of any antibiotic in the treatment of this disease depends on its antibacterial properties and the concentration that remains in the blood and CSF after systemic administration. Unfortunately, during the last few years, sulphonamide-resistant meningcocci have emerged (Lambert, 1974), Haemophilus influenzae is now sometimes resistant to ampicillin because of $\beta$-lactamase production, and meningitis due to chloramphanicol-resistant $H$. influenzae has recently been reported (Kinmonth et al., 1978). Therefore, triple treatment with a sulphonamide, ampicillin, and chloramphenicol is often used before the causative organism is known. Cefuroxime, unlike the other three agents, is highly active against all the organisms that commonly cause meningitis-namely Neisseria meningitidis, $H$. influenzae, and Streptococcus pneumoniae (O’Callaghan et al., 1976). It was felt appropriate, therefore, to determine blood and CSF levels of cefuroxime in children with meningitis before this antibiotic was considered as an alternative treatment.

\section{Patients, methods, and results}

The treatment currently used at this hospital for children with meningitis consists of ampicillin ( $25 \mathrm{mg} / \mathrm{kg}$ ), chloramphenicol ( $15 \mathrm{mg} / \mathrm{kg}$ ), and sulphadimidine $(25 \mathrm{mg} / \mathrm{kg})$, by IV infusion every four hours for a period of up to 5 days. Treatment is modified depending on the sensitivity of the organism to these agents, and then it is continued orally for an additional period of 5 days.

Cefuroxime $(25 \mathrm{mg} / \mathrm{kg})$ was given intravenously by a 20-minute infusion every four hours to 7 children ( 6 boys; age range, $1 \frac{1}{2}-6$ years) for periods of between one and 5 days in addition to the above treatment. The organism responsible for the meningitis in 3 children was $N$. meningitidis (all resistant to sulphadimidine), and in the other 4 it was $H$. influenzae. Sensitivity testing showed that all the isolated organisms were highly sensitive to cefuroxime. Blood samples were taken twice during treatment and plasma levels of cefuroxime were determined between 30 and $90 \mathrm{~min}$ and 4 hours after injection. CSF levels of cefuroxime were measured in 3 patients in whom lumbar punctures were clinically indicated; one child with CSF pressure had lumbar punctures performed 2 hours after a cefuroxime injection on 4 consecutive days. All samples were analysed by a high-pressure liquid chromatography method which enabled cefuroxime to be determined in the presence of other drugs.

Plasma levels of cefuroxime (Figure) determined at between 30 and 90 min and 4 hours after IV infusion 